\title{
Awareness on Preventive Measures taken by Health Care Professionals Attending COVID-19 Patients among Dental Students
}

\author{
Bianca Princeton ${ }^{1}$ Preetha Santhakumar ${ }^{1} \quad$ Lavanya Prathap ${ }^{2}$ \\ ${ }^{1}$ Department of Physiology, Saveetha Dental College \& Hospitals, \\ Address for correspondence Preetha Santhakumar, BHMS, MSc, \\ Saveetha Institute of Medical \& Technical Sciences, Saveetha \\ University, Chennai, India \\ ${ }^{2}$ Department of Anatomy, Saveetha Dental College \& Hospitals, \\ Saveetha Institute of Medical \& Technical Sciences, Saveetha \\ University, Chennai, India \\ Department of Physiology, Saveetha Dental College and Hospitals, \\ Saveetha Institute of Medical \& Technical Sciences, Saveetha \\ University, 162, Poonamallee High road, Chennai-600077, Tamilnadu, \\ India (e-mail: preethas.sdc@saveetha.com).
}

Eur J Dent:2020;14(suppl S1):S105-S109

\begin{abstract}
Objectives Coronavirus disease is an infectious disease caused by a newly discovered coronavirus. This virus primarily spreads through droplets of saliva or discharge from the nose when an infected person coughs or sneezes. This virus was named after its shape, which takes the form of a crown with protrusions around it. The World Health Organization has recommended personal protective equipments (PPE) to doctors and health care workers attending COVID-19 patients. PPE generally includes masks, goggles, respirators, gloves, face shields, and isolation gowns. The principle aim of this study is to create awareness among dental students about the preventive measures taken by health care professionals while attending patients affected with COVID-19.

Materials \& Methods A questionnaire comprising 15 questions was created using an online Google forms website and was circulated among 100 dental students. The survey was conducted within a week in the months of April to May 2020. The results and observations were recorded in the form of pie charts.

Results Ninety-three percent of the participants have stated that health care professionals must clean their hands often, cover their nose and mouth, and maintain safe distance from everyone in order to prevent the virus from affecting them. Sixty-three percent of the participants are familiar with the term PPE. Majority assume that health

Keywords

- coronavirus

- dental students

- health care workers

- safety measures care professionals are given enough safety precautions while treating a patient with coronavirus.

Conclusion Hence, to conclude, health care professionals play a vital role in improving access and quality health care for the population, and hence, they must be protected as well. Since dental students treat patients, they are vulnerable to infection as well, and must take proper safety measures.
\end{abstract}

\section{Introduction}

Coronavirus disease (COVID-19) is an infectious disease caused by a newly discovered coronavirus. The coronavirus is a group of related viruses that cause diseases in mammals and birds. In

DOI https://doi.org/ 10.1055/s-0040-1721296 ISSN 1305-7456. humans, coronavirus can cause respiratory tract infections that range from mild to lethal. This virus primarily spreads through droplets of saliva or discharge from the nose when an infected person coughs or sneezes. The coronavirus polymerase chain reaction test is taken with the help of nasopharyngeal and

(c) 2020. European Journal of Dentistry.

This is an open access article published by Thieme under the terms of the Creative Commons Attribution-NonDerivative-NonCommercial-License, permitting copying and reproduction so long as the original work is given appropriate credit. Contents may not be used for commercial purposes, or adapted, remixed, transformed or built upon. (https://creativecommons.org/licenses/by-nc-nd/4.0/)

Thieme Medical and Scientific Publishers Pvt. Ltd., A-12, 2nd Floor, Sector 2, Noida-201301 UP, India 
oropharyngeal swab, bronchoalveolar lavage, sputum, urine, and blood. ${ }^{1,2}$ The coronavirus mainly affects older people with underlying medical problems like cardiovascular diseases such as myocardial infarction, ${ }^{3}$ diabetes, or any chronic respiratory diseases. ${ }^{4}$ Not only do older people get affected, but also middle-aged people diagnosed with asthma. ${ }^{5}$ Obesity-related conditions seem to worsen the effect of COVID-19. Given the extremely high rates of obesity around the globe, we expect that a high percentage of the population who will contract coronavirus will also have a body mass index over $25 .^{6}$ Additionally, the peak expiratory flow rate decreases with the increase in body mass index. ${ }^{7,8}$ Individuals diagnosed with COVID-19 have reduced respiratory capacity when compared to normal people. In such cases, a conventional oral spirometry is commonly used for respiratory functions. However, the nasal passages are the primary pathway for regulating ventilation and modulating

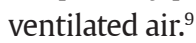

The virus was named after its shape, which it takes the form of a crown with protrusions around it; hence, it was named coronavirus. ${ }^{10}$ The disease claimed over 1.41 million lives globally and infected around 58.8 million people. As of now, there are no specific vaccines or treatments discovered for COVID-19.

While frontline health care workers and patients are facing the brunt of the direct impact of the virus, the consequences have spread far and wide and are facing significant barriers in sleeping. ${ }^{11}$ The world health organization (WHO) has recommended personal protective equipment (PPE) to doctors and health professionals attending COVID-19 patients. The PPE generally includes masks, goggles, gloves, and face shields. ${ }^{12}$ Health care workers must be provided with clean gloves, clean isolation gown, respirators, and eye protection during every patient encounter. If it is reusable, then it should be cleaned thoroughly. Health care workers can also protect themselves by keeping the patient under isolation.

The potential promise of the topic is that, while treating patients, careful execution of infection control measures should take place, since it is necessary to prevent transmission to other patients as well as health care workers. Human-to-human transmission can occur undeniably, and the risk of airborne spread during aerosol-generating medical procedures still remains a concern in specific circumstances. ${ }^{13}$

The experience gained in the studies from other researches ${ }^{14-21}$ has led us to work on awareness about the preventive measures to be taken by doctors during the COVID-19 pandemic. The main principle or aim of the study is to create awareness about the preventive measures to be taken by dental students while treating patients during the COVID-19 pandemic.

\section{Materials and Methods}

The study setting was done through an online survey among dental students. The advantages of online surveys are that it is time saving and involves only a selective group of people. A count of hundred participants participated in the survey. This study was conducted in the month of April to May 2020. A previous study sample was considered with a total number of 2,045 participants, which indicates the number of samples taken in that survey. ${ }^{22}$ The sampling method employed here is the simple random sampling method. For the data collection and tabulation, the questionnaire validity checking was done by consulting an expert. The data collection was done through Google forms, and data manipulation through MS Excel. The results or observations were recorded in the form of pie charts. The descriptive data were analyzed statistically using SPSS software. The correlation analysis for different parameters like gender was done through Chi-square test, with the help of SPSS software, and was depicted in the form of bar charts. The list of independent variables includes age and education, whereas the dependent variable comprises awareness among dental students and knowledge.

\section{Results}

The responses of the survey were collected and tabulated in the form of a (-Table. 1). When enquired about the awareness of the recent pandemic caused due to coronavirus, all the dental students responded positively. When questioned

Table 1 The table represents the responses of the participants to the following questions

\begin{tabular}{|l|l|l|l|}
\hline No. & Question & Yes (\%) & No (\%) \\
\hline 1 & Awareness of recent pandemic caused due to coronavirus & 99 & 1 \\
\hline 2 & Health care workers at risk from the virus & 89 & 11 \\
\hline 3 & Origination of the name of the virus & 40 & 60 \\
\hline 4 & Familiarity with the term PPE & 63 & 37 \\
\hline 5 & Awareness of the preventive measures taken during the pandemic & 96 & 4 \\
\hline 6 & Awareness of the age group that is at most risk from the virus & 89.5 & 30 \\
\hline 7 & $\begin{array}{l}\text { Awareness of the safety measures followed by health care professionals } \\
\text { during COVID-19 }\end{array}$ & 70 & 24 \\
\hline 8 & Similarity of the coronavirus to SARS and MERS & 76 & 15 \\
\hline 9 & Awareness of the components of PPE & 85 & 24 \\
\hline 10 & $\begin{array}{l}\text { Awareness of a molecular test that is performed on health care workers who } \\
\text { possessed the symptoms of coronavirus }\end{array}$ & 76 & \\
\hline
\end{tabular}

Abbreviations: COVID-19; coronavirus disease 2019; MERS, Middle East respiratory syndrome; PPE, personal protective equipment; SARS, severe acute respiratory syndrome. 
whether the health care workers are at risk from coronavirus, $89 \%$ of the participants affirmed to the statement. Majority believe that the coronavirus is named after its shape. Thirtyseven percent of the dental students were not aware of the term PPE. Ninety-six percent of the participants were aware of the preventive measures taken during the pandemic. Most of the participants of this survey think that the health care professionals follow each and every safety measure while treating COVID-19 patients. Seventy-six percent of the respondents have agreed to the statement that coronavirus is similar to severe acute respiratory syndrome (SARS) and the Middle East respiratory syndrome (MERS). Around 85\% of the participants are aware of the components of PPE. The association between gender and the awareness of the recent pandemic was evaluated, with the help of Chi-square test. A $p$-value more than 0.05 , is considered to be not statistically significant (-Fig. 1). Similarly, the correlation analysis between gender and health care workers at risk from the virus was determined with the help of Chi-square test, where $p$-value is more than 0.05 , which is statistically insignificant (-Fig. 2). The gender and origin of the name of the virus were correlated using the Chi-square test. Statistically, $p$-value is

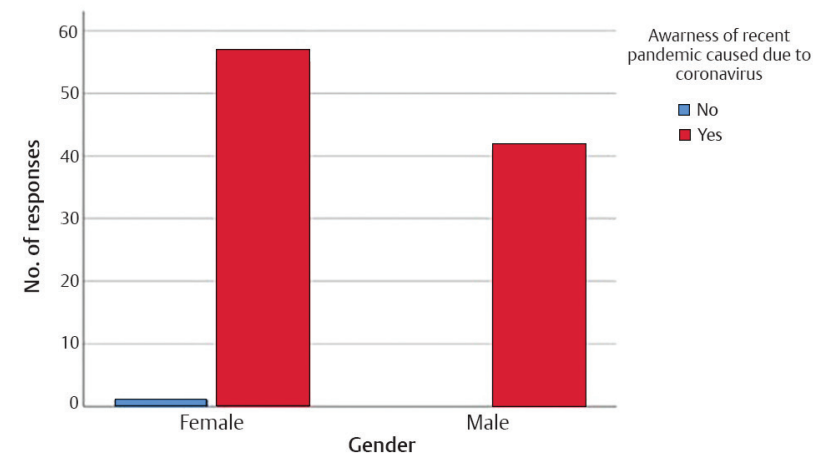

Fig. 1 The graph depicts the association between gender and awareness of the recent pandemic caused due to COVID 19. X-axis represents gender and $\mathrm{Y}$-axis, number of responses. Blue bar represents no and red bar, yes. Females were more aware than the males. Chi-square test, $p=0.3(p>0.05)$ and it is statistically not significant.

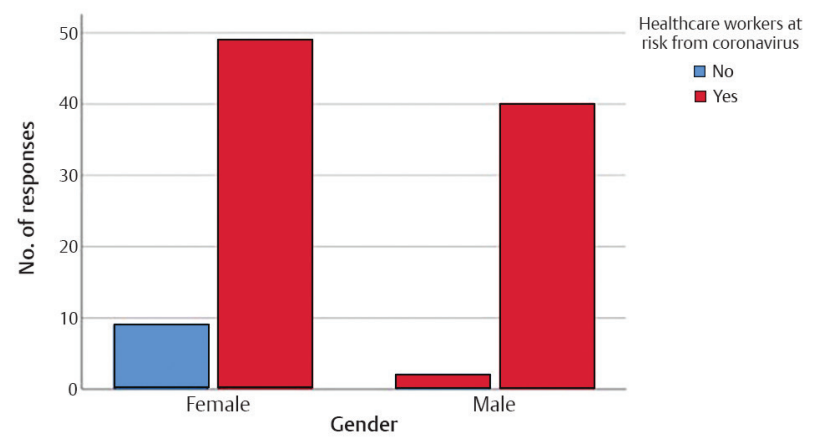

Fig. 2 The graph depicts the association between gender and awareness of the health care workers at risk from coronavirus. $X$-axis represents gender and $\mathrm{Y}$-axis, number of responses. Blue represents no, and red color, yes. Females were more aware than the males. Chi-square test, $p=0.3(p>0.05)$ and it is statistically not significant. equal to 0.782 , which is insignificant ( - Fig. 3 ). The association between gender and awareness of PPE was analyzed. The $p$-value is more than 0.05 , which is statistically insignificant (-Fig. 4).

\section{Discussion}

Participants of the survey were questioned whether the virus was caused by an animal. The response to this question was affirmative. The key reservoirs, that is, mode of the transmission of coronavirus, especially the $\alpha$ and $\beta$ coronaviruses have the ability to infect humans through the consumption of infected animals as a source of food, which is the major cause of animal to human transmission. ${ }^{23}$ Any close contact with an infected person results in the transmission of the virus to a healthy person. Rhinolophus bats are found to have anti-SARS coronavirus antibodies, suggesting that bats are a source of viral replication. Primary examination of environmental specimens tested positive for COVID-19 in the Wuhan seafood market. Based on the WHO report, it was confirmed

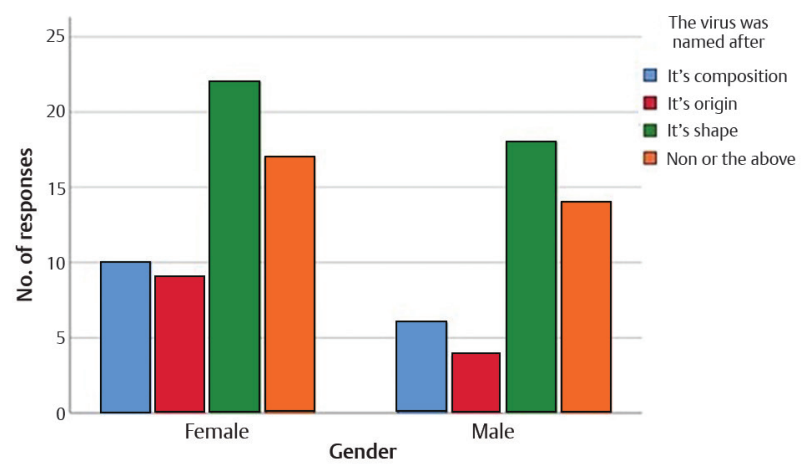

Fig. 3 The graph depicts the association between gender and awareness of the origin of the name of the virus. $X$-axis represents gender and $Y$-axis, number of responses. Blue represents its composition; red, origin; green, its shape; orange, none of the above. Females were comparatively aware of the origin of the name of the virus than males. Chisquare test, $p=0.782(p>0.05)$ and it is statistically not significant.

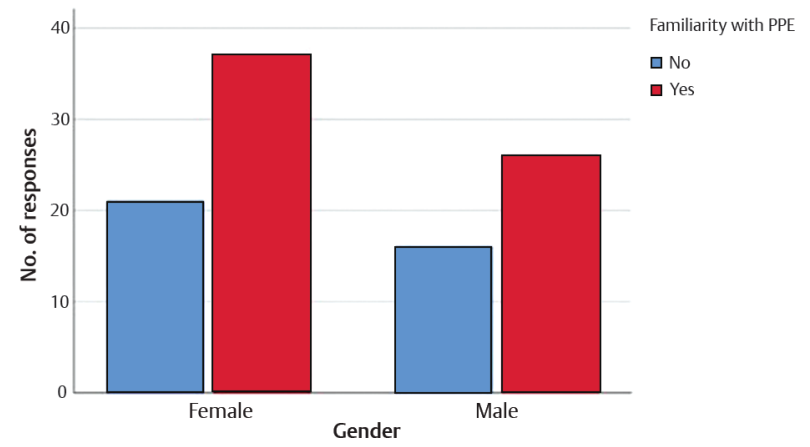

Fig. 4 The graph depicts the association between gender and the familiarity of the term personal protective equipment. X-axis represents gender and $\mathrm{Y}$-axis, number of responses. Blue bar represents no and red bar, yes. Females were more aware than the males. Chi-square test, $p=0.012(p<0.05)$ and it is statistically significant. 
that the market place deemed positive for the coronavirus disease, and there was no specific association with any animal. ${ }^{24}$

Is the novel coronavirus similar to SARS and MERS? $76 \%$ of the participants agreed the close resemblance similarity to SARS and MERS. Coronavirus is similar to those causing MERS and SARS. ${ }^{25}$ Both these syndromes are reported to spread through natural aerosols from human to human. It also has similarities of pathogens and its region of exposure. Despite heightened public awareness and strong interventional response, COVID-19 is already more widespread than SARS and indicates that it is more transmissible. ${ }^{26}$

The dental students were questioned whether health care workers are at risk, and $89 \%$ of them have responded affirmatively. Coronavirus disease-2019 originated in Wuhan, China and caused or infected many health care workers. Seventy-two health care workers were manifested with acute respiratory illness, and they were enrolled to analyze the risk factors. The high-risk department, longer duty hours, and suboptimal hand hygiene after having contact with patients are linked to COVID-19. ${ }^{27}$ To prevent the health care professionals from being affected by the virus, WHO implemented the usage of PPE among doctors as well as health care workers. General hygiene practices like handshakes were avoided, frequent air changes in rooms, physical separation of suspected infected patients, frequent disinfection of room, and avoiding overcrowded places were reinforced among health care workers. ${ }^{28,29}$ It was also observed that crossinfection can take place through dental operations such as suction tubes, etc. Hence, the instruments must be disinfected thoroughly. Other notable studies prove that dental health professionals must be provided with additional knowledge regarding the disinfection guidelines, particularly during the COVID-19 crisis $^{30}$.

The limitations of the study are that it is a preliminary survey, with less study population, and it was conducted through an online platform.

The future scope of the study is that it will create awareness among the dental students as well as health care workers about preventive measures to be taken. Furthermore, studies should also be carried out. Limitations are to be explored in the future.

\section{Conclusion}

In this study, awareness was created especially about the preventive measures of health care workers to be taken during the COVID-19 ongoing pandemic. Health care professionals play a central and critical role in improving access and quality health care for the population. Since dental students treat patients, they are vulnerable to infection as well and hence are obliged to take proper safety measures.

\section{Conflict of Interest}

None declared.

\section{Acknowledgements}

This research was done under the supervision of the department of research of our institution. The team extends our sincere gratitude to the corresponding guides for their constant support and successful completion of this work.

\section{References}

1 Hamid H, Khurshid Z, Adanir N, Zafar MS, Zohaib S. COVID19 pandemic and role of human saliva as a testing biofluid in point-of-care technology 2020. Eur J Dent 2020;14(suppl S1):S123-S129 doi:10.1055/s-0040-1713020

2 Khurshid Z, Asiri FYI, Al Wadaani H. Human saliva: Noninvasive fluid for detecting novel coronavirus (2019-nCoV). Int J Environ Res Public Health 2020;17(7):2225 doi:10.3390/ ijerph17072225

3 Renuka S, Sethu G. Regeneration after myocardial infarction. Research J Pharm and Tech 2015;8(6):738-741

4 Remuzzi A, Remuzzi G. COVID-19 and Italy: what next?. Lancet 2020;395(10231):1225-1228 doi:10.1016/S01406736(20)30627-9

5 Dave PH, Preetha. Pathogenesis and novel drug for treatment of asthma: a review. Research J Pharm and Tech 2016;9(9): 1519-1523

6 Baharat MM, Gayatri Devi R. Obesity in relation to Infertility. Research J Pharm and Tech 2018;11(7):3183-3185

7 Timothy CN, Gayatri Devi R, Jothi Priya A. Evaluation of peak expiratory flow rate (PEFR) in pet owners. Indian J Public Health Research Develop 2019;10(8):803

8 Fathima F, Preetha P. Evaluation of thyroid function test in obese patients. Asian J Pharm Clin Res 2016;9(s3);353-355

9 Gayatri DR, Sethu G. Evaluation of adenoids by oronasal and nasal spirometry. Asian J Pharm Clin Res 2018;11(10);272-274

10 Bai Y, Yao L, Wei T, et al. Presumed Asymptomatic Carrier Transmission of COVID-19. JAMA 2020;323(14):1406-1407 doi:10.1001/jama.2020.2565

$11 \mathrm{Rj}$ I, Devi G. Role of environmental factors on sleep patterns of different age groups: A survey-based study. Asian J Pharm Clin Res 2016;9(6):124-126

12 Covid C, Team R; CDC COVID-19 Response Team. Severe outcomes among patients with Coronavirus disease 2019 (COVID-19)-United States, February 12-March 16, 2020. MMWR Morb Mortal Wkly Rep 2020;69(12):343-346

13 Wax RS, Christian MD. Practical recommendations for critical care and anesthesiology teams caring for novel coronavirus (2019-nCoV) patients. Can J Anaesth 2020;67(5):568-576 doi:10.1007/s12630-020-01591-X

14 Samuel AR, Devi MG. Geographical distribution and occurrence of Endemic Goitre. Research J Pharm and Tech 2015;8(8):973978 doi:10.5958/0974-360X.2015.00162.6

15 Harsha L, Priya J, Shah KK, Reshmi B. Systemic approach to management of neonatal jaundice and prevention of kernicterus. Research J Pharm and Tech 2015;8(8):1087-1092

16 Abigail A, Priya J, Devi G. Evaluation of muscular endurance among dentists. Indian J Public Health Research Develop 2019;10(10):258

17 David D, Jothi PA, Devi G. Physical fitness among the dental physician, dental undergraduates and postgraduates students. Indian J Public Health Research Develop 2019;10(10):223

18 Shruthi M, Preetha S. Effect of simple tongue exercises in habitual snorers. Research J Pharm and Tech 2018;11(8): 3614-3616. doi:10.5958/0974-360X.2018.00665.0

19 Choudhari S, Jothipriya MA. Non-alcoholic fatty liver disease. Research J Pharm and Tech 2016;9(10):1782-1785 
20 Iyer PK, Gayatri Devi R, Jothi Priya A. A survey study on causes, treatment and prevention of onychocryptosis. Indian J Public Health Research Develop 2019;10(8):807

21 Swathy S, Sethu VG. Acupuncture and lower back pain. Research J Pharm Techn 2015;8(8):991-993

22 Moro M, Vigezzi GP, Capraro M, et al. 2019-novel coronavirus survey: knowledge and attitudes of hospital staff of a large Italian teaching hospital. Acta Biomed 2020;91(3-S):29-34

23 Shereen MA, Khan S, Kazmi A, Bashir N, Siddique R. COVID-19 infection: Origin, transmission, and characteristics of human coronaviruses. J Adv Res 2020;24:91-98

24 Sarfraz I, Rasul A, Hussain G, Adem S, Ali M. Natural immune boosters as first-line armours to combat viral infection COVID19: Myth or science?. Preprints 2020:2020030427 doi: 10.20944/preprints202003.0427.v1

25 Schwartz DA, Graham AL. Potential maternal and infant outcomes from (Wuhan) Coronavirus 2019-nCoV infecting pregnant women: Lessons from SARS, MERS, and other human coronavirus infections. Viruses 2020;12(2):194 doi:10.3390/ v12020194
26 Misra V, Bhardwaj A, Bhardwaj S, Misra S. Novel COVID19-origin, emerging challenges, recent trends, transmission routes and control-a review. journal of contemporary. J Contemp Orthod 2020;4(1):57-67

27 Chen X, Ran L, Liu Q, Hu Q, Du X, Tan X. Hand hygiene, mask-wearing behaviors and its associated factors during the COVID-19 epidemic: A cross-sectional study among primary school students in Wuhan, China. Int J Environ Res Public Health 2020;17(8):2893 doi:10.3390/ijerph17082893

28 Vimercati L, Dell'Erba A, Migliore G, et al. Prevention and protection measures of healthcare workers exposed to SARSCoV-2 in a university hospital in Bari, Apulia, Southern Italy. J Hosp Infect 2020;105(3):454-458

29 Tariq R, Hamid H, Mashood S, et al. Common misconceptions regarding COVID-19 among health care professionals: an online global cross-sectional survey. J Oral Res 2020;Covid19.S2(1):36-45

30 Sarfaraz S, Shabbir J, Mudasser MA, et al. Knowledge and attitude of dental practitioners related to disinfection during the COVID-19 pandemic. Healthcare (Basel) 2020;8(3):232 doi:10.3390/healthcare8030232 